\title{
Early onset cerebellar ataxia with retained reflexes: a clinical and genetic conundrum
}

Ataxia cerebelar de início precoce com reflexos mantidos: um enigma clínico e genético

Hélio A. G. Teive

MD, PhD; Head of Neurology

Service, Hospital de Clínicas, Federal University of Paraná (UFPR), Curitiba PR, Brazil.

\section{Correspondence}

Hélio A. G. Teive

Rua General Carneiro 1103/102 80060-150 Curitiba PR - Brasil

E-mail:hagteive@mps.com.br Conflict of interest

There is no conflict of interest to declare.

Received 29 April 2013 Accepted 07 May 2013
1 taxia is a broad term that literally means "without order". The term locomotor ataxia has been most commonly used to refer to motor incoordination. The most widely recognized form, cerebellar ataxia (CA), can be classified as primary, idiopathic, acquired (or secondary) and sporadic ${ }^{1}$. Primary, CAs are further subdivided into congenital and hereditary, the latter including autosomal recessive (ARCA), autosomal dominant (ADCA) - currently known as spinocerebellar ataxias (SCAs) - X-linked CAs and mitochondrial ataxias ${ }^{1}$. Autosomal recessive cerebellar ataxias (ARCA) are part of a large heterogeneous group of hereditary ataxias ${ }^{2}$. ARCA are typically characterized by degeneration of the cerebellum and spinal cord and relatively early onset of symptoms (before the age of 20 years). Clinically, impaired gait and balance, motor incoordination, action tremor and dysarthria are almost always present, although other neurological signs and symptoms may be observed ${ }^{1,2}$. ARCA include Friedreich's ataxia (FA), considered the commonest form worldwide, and a large group of other rarer genetic disorders, such as the entity defined as early-onset cerebellar ataxia with retained reflexes (EOCARR), which is also known as Harding's ataxia ${ }^{1,2}$. FA is estimated to have a prevalence of 2-4/100,000, while ataxia telangiectasia has a prevalence of $1-2.5 / 100,000$, and EOCARR a prevalence of 1/100,000. Other forms of ARCA are much less common ${ }^{3}$.In 1981, Harding published a seminal study in which he evaluated 20 patients with EOCARR with a clinical picture characterized by progressive cerebellar ataxia developing within the first two decades of life associated with dysarthria, pyramidal signs and increased knee jerks and upper limb reflexes, probably with autosomal recessive inheritance ${ }^{2}$. This nosological entity was later confirmed by other authors, including Filla et al. in Italy and Klockgether et al. in Germany ${ }^{4,5}$. EOCARR then became considered a differential diagnosis for FA and its variants such as Friedreich ataxia with retained reflexes (FARR) ${ }^{1-5}$. The main point of discussion regarding FA and EOCARR concerns their genetic differences: whereas the genetic cause of FA has been defined (the presence of a GAA triplet repeat expansion in the first intron of the FA gene, on the proximal long arm of chromosome 9), the genetic cause of EOCARR remains unknown, and to date there has only been one study of the condition (in a Tunisian family), in which a locus on chromosome 13q11-12 was identified, but not the causative gene $\mathrm{e}^{1,3,6}$. In this issue of Arquivos de Neuro-Psiquiatria, Pedroso et al. published an interesting study of the clinical spectrum of EOCARR ${ }^{7}$. They evaluated 12 patients from different families with established diagnoses of EOCARR, focusing on the main clinical manifestations. This Brazilian series of EOCARR patients was notable because the disorder was the second most common form of ARCA after FA. The most significant clinical findings, in addition to autosomal recessive inheritance and consanguinity in 50\% of cases, were cerebellar ataxia with dysarthria, retained reflexes associated or not with peripheral neuropathy and cerebellar atrophy on brain magnetic resonance imaging $(\mathrm{MRI})^{7}$. Harding described EOCARR as being the second most common form of ARCA after FA, a similar finding to that reported by Filla et al. In a review of ARCA, Palau and Espinós noted that EOCARR is the third most common form of ARCA after AF and ataxia telangiectasia ${ }^{2-4}$. Interestingly, none of the reviews of ARCA published in the last two years even 
mention a diagnosis of $\mathrm{EOCARR}^{8,9}$. In fact, the major discussion about the diagnosis of EOCARR revolves around the fact that the disorder can be considered a heterogeneous group of diseases with different genetic substrates and similar phenotypes. This problem is not unusual in clinical neurological practice. At the end of the $19^{\text {th }}$ century, forms of hereditary ataxias that were clinically different from that described by FA were studied by Pierre Marie, a disciple of Charcot, and were known as Marie's ataxia. The concept of Marie's ataxia lasted for a considerable time and represented a group of disorders that were different from FA. The form of ataxia known as Marie's ataxia was later defined to actually represent a heterogeneous group of ataxias with different causes, including forms of autosomal dominant cerebellar ataxia $(\mathrm{SCA})^{2}$.Hence, EOCARR may represent a complex entity with multiple genetic causes, making further genetic studies necessary to elucidate this question and define the nosological diagnosis accurately ${ }^{10}$. Until such studies are carried out, any investigation of ARCA and EOCARR in particular must include a large number of diseases besides ataxia with vitamin E deficiency, ataxia-telangiectasia and ataxia with oculomotor apraxia types 1 and 2, such as autosomal recessive spastic ataxia of Charlevoix-Saguenay (ARSACS), infantile-onset spinocerebellar ataxia (IOSCA), Marinesco-Sjögren syndrome, Krabbe disease, hexosaminidase A deficiency, cerebrotendinous xanthomatosis, spinocerebellar ataxia with axonal neuropathy (SCAN1), autosomal-recessive cerebellar ataxia type 1 (ARCA1 - with mutations in the SYNE 1 gene), coenzyme Q10 deficiency with cerebellar ataxia, and mitochondrial recessive ataxia syndrome (MIRAS) $)^{1,3}$.

\section{References}

1. Teive HAG, Munhoz RP, Ashizawa T. Inherited and sporadic ataxias. In: Albanese A, Jankovic J (eds). Hyperkinetic movement disorders. Oxford, UK: Wiley-Blackwell; 2012. p. 279-295.

2. Harding AE. Early onset cerebellar ataxia with retained tendon reflexes: a clinical and genetic study of a disorder distinct from Friedreich's ataxia.J Neurol Neurosurg Psychiatry 1981;44:503-508.

3. Palau F, Espinós C. Autosomal recessive cerebellar ataxias. Orphanet J Rare Dis 2006;1:47.

4. Filla A, De Michele G, Cavalcanti F, et al. Clinical and genetic heterogeneity in early onset cerebellar ataxia with retained reflexes. J Neurol Neurosurg Psychiatry 1990;53:667-670.

5. KlockgheterT, Petersen D, Grodd W, Dichgans J. Early onset cerebellar ataxia with retained reflexes. Clinical, electrophysiological and MRI observations in comparison with Friedreich's ataxia. Brain 1991;114:1559-1573.

6. Mrissa N, Belal S, Hamida CB, et al. Linkage to chromosome 13q1112 of an autosomal recessive cerebellar ataxia in a Tunisian Family. Neurology 2000;54:1408-1414.

7. Pedroso JL, Braga-Neto P, Ricarte IF, de Albuquerque MVC, Barsottini OGP. Clinical spectrum of early onset cerebellar ataxia with retained reflexes. Arq Neuropsiquiatr 2013;71:345-348.

8. Anheim M,Tranchant C, Koenig M. The autosomal recessive cerebellar ataxias. N Engl J Med 2012;366:636-646.

9. Sailer A, Houlden $\mathrm{H}$. Recent advances in the genetics of cerebellar ataxias. Curr Neurol Neurosci Rep 2012;12:227-236.

10. De Michele G, Filla A. Other autosomal recessive and childhood ataxias. Handb Clin Neurol 2012;103:343-357. 